University of Nebraska - Lincoln

DigitalCommons@University of Nebraska - Lincoln

Agronomy \& Horticulture - Faculty Publications

Agronomy and Horticulture Department

$5-29-2003$

\title{
Identification of QTLs and Environmental Interactions Associated with Agronomic Traits on Chromosome 3A of Wheat
}

\author{
B. T. Campbell \\ P. Stephen Baenziger \\ University of Nebraska-Lincoln, pbaenziger1@unl.edu \\ K. S. Gill \\ Washington State University, Pullman, Washington \\ Kent M. Eskridge \\ University of Nebraska-Lincoln, keskridge1@unl.edu \\ H. Budak \\ University of Nebraska-Lincoln
}

Rice Exp. Station, Calif. Coop. Rice Res. Foundation, Biggs, CA, todd.campbell@ars.usda.gov

See next page for additional authors

Follow this and additional works at: https://digitalcommons.unl.edu/agronomyfacpub

Part of the Plant Sciences Commons

Campbell, B. T.; Baenziger, P. Stephen; Gill, K. S.; Eskridge, Kent M.; Budak, H.; Erayman, M.; Dweikat, Ismail M.; and Yen, Y., "Identification of QTLs and Environmental Interactions Associated with Agronomic Traits on Chromosome 3A of Wheat" (2003). Agronomy \& Horticulture -- Faculty Publications. 27.

https://digitalcommons.unl.edu/agronomyfacpub/27

This Article is brought to you for free and open access by the Agronomy and Horticulture Department at DigitalCommons@University of Nebraska - Lincoln. It has been accepted for inclusion in Agronomy \& Horticulture -Faculty Publications by an authorized administrator of DigitalCommons@University of Nebraska - Lincoln. 


\section{Authors}

B. T. Campbell, P. Stephen Baenziger, K. S. Gill, Kent M. Eskridge, H. Budak, M. Erayman, Ismail M. Dweikat, and Y. Yen 


\title{
Identification of QTLs and Environmental Interactions Associated with Agronomic Traits on Chromosome 3A of Wheat
}

\author{
B. T. Campbell, P. S. Baenziger,* K. S. Gill, K. M. Eskridge, H. Budak, M. Erayman, I. Dweikat, and Y. Yen
}

\begin{abstract}
Genetic analyses of complex traits in wheat (Triticum aestivum $\mathbf{L}$.) are facilitated by the availability of unique genetic tools such as chromosome substitution lines and recombinant inbred chromosome lines (RICLs) which allow the effects of genes on single chromosomes to be studied individually. Chromosome $3 \mathrm{~A}$ of 'Wichita' is known to contain alleles at quantitative trait loci (QTLs) that influence variation in grain yield and agronomic performance traits relative to alleles of 'Cheyenne'. To determine the number, location, and environmental interactions of genes related to agronomic performance on chromosome 3A, QTL and QTL $\times$ environment analyses of 98 RICLs-3A were conducted in seven locations across Nebraska from 1999 through 2001. QTLs were detected for seven of eight agronomic traits measured and generally localized to three regions of chromosome $3 \mathrm{~A}$. QTL $\times$ environment interactions were detected for some QTLs and these interactions were caused by changes in magnitude and crossover interactions. Major QTLs for kernels per square meter and grain yield were associated within a 5-centimorgan (cM) interval and appeared to represent a single QTL with pleiotropic effects. This particular QTL displayed environmental interactions caused by changes in magnitude, wherein the positive effect of the Wichita QTL allele was larger in higher yielding environments.
\end{abstract}

G RAIN YIELD AND AGRONOMIC PERFORMANCE are the most commonly measured, but poorly understood crop traits. Modern strategies for investigating the genetic basis of grain yield and agronomic performance were first established in the 1980s with the use of molecular markers to construct genetic linkage maps in discrete populations (Edwards et al., 1987; Lander and Botstein, 1989; Stuber et al., 1987; Tanksley et al., 1982). Information from genetic linkage maps and agronomic data collected from field experiments allowed the identification of QTL associated with agronomic trait variability. The aim of QTL studies is to provide a framework for understanding complex traits by identifying and measuring the relative impact of alleles at a mapped chromosomal region. The identified QTLs can also be used by plant breeders using marker assisted selection (MAS) to increase breeding efficiency (Dudley, 1993).

Scientists conducting QTL experiments in wheat have access to unique genetic resources, including chromosome substitution lines. Evaluating reciprocal chromo-

B.T. Campbell, Rice Exp. Station, Calif. Coop. Rice Res. Foundation, Biggs, CA 95917; P. S. Baenziger, H. Budak, M. Erayman, I. Dweikat, Dep. of Agronomy and Horticulture, Univ. of Nebraska, Lincoln, NE 68583; K. S. Gill, Dep. of Crop and Soil Sciences, Washington State Univ., Pullman, WA 99164; K. M. Eskridge, Dep. of Biometry, Univ. of Nebraska, Lincoln, NE 68583; Y. Yen, Dep. of Biology and Microbiology, South Dakota State Univ., Brookings, SD 57007. Research partially funded by USDA, NRICGP 00-353000-9266. Nebraska Agricultural Research Division, Journal Series No. 13824. Received 28 Sept. 2002. *Corresponding author (pbaenziger1@unl.edu).

Published in Crop Sci. 43:1493-1505 (2003). some substitution lines between two parental lines for complex traits allows for the identification of single chromosomes containing QTLs for those traits (Berke et al., 1992a,b; Cantrell and Joppa, 1991). Single reciprocal chromosome substitution lines can be targeted for development of RICLs that segregate only for genes on that chromosome (Shah et al., 1999a,b; Joppa et al., 1997). RICL populations present a powerful tool to conduct QTL studies, especially in wheat, which has the largest genome size of the cereals at $16000 \mathrm{Mbp}$ (Arumuganathan and Earle, 1991). Kaeppler (1997) documented the advantage of using RICL populations to detect QTLs in wheat, by showing the statistical power of 50 RICLs was equal to that of 200 recombinant inbred lines, when considering a Type I error rate of $5 \%$. The power of 100 RICLs $(0.98)$ exceeded that of 200 recombinant inbred lines $(0.41)$ by a factor of 2.4 times, when considering a Type I error rate of $1 \%$. Because of these advantages, RICL populations have been created to study grain yield, grain protein, and other agronomic traits in wheat (Araki et al., 1999; Joppa et al., 1997; Kato et al., 1999, 2000; Shah et al., 1999a,b).

The analysis of grain yield and agronomic traits controlled by genes on chromosome 3A in Nebraska was initiated in the 1980s. Berke et al. (1992a,b) evaluated a full set of reciprocal chromosome substitution lines between cv. Cheyenne (CNN) and cv. Wichita (WI) for grain yield and other agronomic traits and reported that chromosome 3A from WI increased grain yield 12 to $15 \%$ when placed in CNN background. This research led to the development of a set of 50 chromosome $3 \mathrm{~A}$ recombinant inbred chromosome lines (RICLs-3A), derived from a cross between CNN and CNN (WI3A) (Shah et al., 1999a,b). Shah et al. (1999a,b) evaluated the 50 RICLs-3A lines for anthesis date, plant height, grain volume weight, grain yield, 1000-kernel weight, spikes per square meter, and kernels per spike. Anthesis date (Eps) was mapped as a single gene on the short arm of chromosome $3 \mathrm{~A}$ and explained significant variation for 1000 kernel weight, kernels per spike, and plant height. Additional QTLs were detected for yield components and plant height elsewhere on the chromosome. However, QTLs for grain yield per se were not detected.

The inability to map QTLs for grain yield could be attributed to the interaction of yield component QTLs, hence no single grain yield locus could be identified. QTL $\times$ E interactions $(\mathrm{QEI})$ of the crossover type could

\footnotetext{
Abbreviations: AD, anthesis date; cM, centimorgan; GEI, genotype $\times$ environment interaction; GVWT, grain volume weight; GYLD, grain yield; KPS, kernel number spike ${ }^{-1}$; KPSM, kernel number $\mathrm{m}^{-2}$; PHT, plant height; QTL, quantitative trait locus; QEI, QTL $\times$ environment interaction; RICLs, recombinant inbred chromosome lines; SPSM, spike number $\mathrm{m}^{-2}$; TKWT, 1000-kernel weight.
} 
also influence the ability to detect QTLs for grain yield. Shah et al. (1999b) detected QTLs for grain yield in individual environments, but individual QTLs were not consistently detected across environments. Inconsistent QTL detection has been observed and attributed to QEI in other grain yield QTL studies in wheat (Araki et al., 1999; Kato et al., 2000) and other crop plants (Beavis and Keim, 1996; Hayes et al., 1993; Lu et al., 1997; Paterson et al., 1991; Sari-Gorla et al., 1997).

Often QEI are reported in terms of QTL detection in individual environments. Analysis of variance (ANOVA) procedures can be employed to detect statistically significant QEI (Sari-Gorla et al., 1997; Zhu et al., 1999). Another approach to study QEI, not currently reported, could be to extend the concept of stability analysis (Eberhart and Russell, 1966) to select for environmentally stable experimental lines in advanced, agronomic performance trials. Just as breeders attempt to select for environmentally stable experimental lines for cultivar release, utilization of MAS to select for environmentally stable QTLs is important to identify and select QTLs for MAS. Various stability statistics (Kang, 1993; Lin et al., 1986) also could be extended to evaluate the stability of lines within a mapping population by separating and comparing lines based on marker (QTL) genotype.

In addition to the biological explanations for the absence of grain yield QTLs on chromosome 3A of wheat (Shah et al., 1999b), the use of two- and three-replication, randomized complete block designs (RCBD) to measure grain yield could have resulted in insufficient statistical power to detect important, but small, trait variation among the lines. Shah et al. (1999a,b) suggested increasing both the number of RICLs-3A used for QTL mapping and the number of replications to decrease experimental error, thus providing more precise measurements of grain yield within and across environments.

On the basis of these recommendations, we evaluated a population of 98 RICLs-3A for grain yield and other agronomic traits in seven environments. An incomplete block design was used to enhance statistical precision. The objective of this study was to identify QTLs and QEI for eight agronomic traits [anthesis date (AD), plant height (PHT), grain volume weight (GVWT), grain yield (GYLD), 1000-kernel weight (TKWT), spikes per square meter (SPSM), kernels per spike (KPS), and kernels per square meter (KPSM)] present on chromosome $3 \mathrm{~A}$ on the basis of agronomic evaluations in seven environments.

\section{MATERIALS AND METHODS}

\section{Plant Materials and Trait Evaluations}

A population of 98 chromosome 3A RICLs was used to study AD, PHT, GVWT, GYLD, TKWT, SPSM, KPS, and KPSM in wheat. Traits were measured following the procedures outlined by Shah et al. (1999a), with the exception that GYLD was measured by harvesting all four rows with a small plot combine and KPSM was calculated as plot yield divided by kernel weight. The development of the first 50 RICLs-3A was previously described by Shah et al. (1999a,b), and the second 48 RICLs-3A by Yen and Baenziger (1992). The 98 lines, CNN, CNN (WI3A), three commonly grown cultivars (Arapahoe, Pronghorn, Jagger) and Wichita were grown in replicated field trials at Lincoln in 1999 to 2001, Mead in 2000 to 2001, and Sidney, NE, in 2000 to 2001 for a total of seven environments. The environments are diverse and representative of wheat producing areas of Nebraska (Peterson, 1992).

At Lincoln 1999, the 104 entries were evaluated in a RCBD with four replications. In 2000 and 2001, the 104 entries were evaluated in a four-replication, incomplete block design (ICBD), where each replication consisted of eight incomplete blocks of thirteen entries. Each entry was grown in a fourrow plot that was $2.4 \mathrm{~m}$ long with $30 \mathrm{~cm}$ between rows. Seeding rate and plot management were in accordance with local practice. An application of Tilt (1-[[2-(2,4-dichlorophenyl)-4-propyl-1, 3-dioxlan-2-yl] methyl-1H-1, 2,4 trizole; Syngenta, Greensboro, NC) was applied according to the recommended rate approximately 1 -wk postanthesis at Lincoln and Mead locations to control fungal diseases.

\section{Field Data Analysis}

Data for each trait were analyzed for normality by PROC UNIVARIATE (SAS Institute, 1999). An analysis of variance (ANOVA) was conducted in each environment by PROC GLM coupled with the RANDOM statement to test significant differences among the RICLs-3A, and between the parents, CNN and CNN (WI3A) (SAS, 1999). Homogeneity of variance tests were conducted to determine if data from individual environments (E) could be pooled to conduct a combined ANOVA across environments to evaluate GEI. For the combined analysis, genotypes and GEI were partitioned into relevant sources of variation, including RICLs-3A, CNN vs. $\mathrm{CNN}(\mathrm{WI} 3 \mathrm{~A}), \mathrm{RICLs}-3 \mathrm{~A} \times \mathrm{E}$, and $\mathrm{CNN}$ vs. $\mathrm{CNN}(\mathrm{WI} 3 \mathrm{~A}) \times$ E (Table 1). Phenotypic correlations for the 98 RICLs-3A were conducted in individual environments and pooled across environments by means of adjusted least squares means (LSMEANS) (SAS, 1999), with the objective of identifying traits that may be correlated and thus controlled by separate trait QTLs that are linked, or one QTL that is pleiotropic for those traits.

\section{Molecular Marker and QTL Analysis}

Genomic DNA was extracted from young leaves following the procedure described by Saghai-Maroof et al. (1984). Restriction fragment length polymorphism (RFLP) and microsatellite markers were used to construct a linkage map of chromosome 3A. Clones used in RFLP analyses were kindly provided by the USDA-ARS central probes repository, Albany, CA, Professor M. D. Gale, John Innes Centre, Norwich, UK, and Dr. A. Graner, Federal Center for Breeding Research on Cultivated Plants, Grünbach, Germany. Genomic DNA digestion, Southern blot analyses, probe labeling and purification, hybridization, and autoradiography were performed as described by Gill et al. (1991).

Microsatellite primer sequences from wheat were identified from Röder et al. (1998) and kindly provided by Dr. P. Cregan, USDA-ARS, Beltsville, MD. Polymerase chain reaction (PCR) reactions were conducted following the procedure outlined by Röder et al. (1998), with minor modifications. PCR products were size separated on $12 \%(\mathrm{w} / \mathrm{v})$ polyacrylamide gels (37:1 acrylamide:bisacrylamide) in TAE buffer $(40 \mathrm{mM}$ Tris-acetate, $20 \mathrm{~m} M$ sodium acetate, $1 \mathrm{~m} M$ EDTA, $\mathrm{pH}$ 7.6) at $300 \mathrm{~V}$ for $4 \mathrm{~h}$. Gels were stained in a $1 \mu \mathrm{g} \mathrm{mL}-1$ ethidium 
bromide solution for $30 \mathrm{~min}$, destained in distilled water for $2 \mathrm{~h}$, and visualized under UV light.

Heterogeneity of marker segregation in the first 50 RICLs$3 \mathrm{~A}$ and second 48 RICLs-3A sub-populations was evaluated to determine if subpopulations could be pooled (Liu, 1997). Marker segregation in the combined RICLs-3A population was evaluated using goodness of fit tests using the expected 1:1 Mendelian segregation ratio (Liu, 1997). Linkage map construction was conducted by MAPMAKER/EXP 3.0 (Lincoln et al., 1992) with the distance unit set to recombination fractions. The GROUP command with a LOD threshold of 5.0 and an independent distance of $50 \mathrm{cM}$ was used to assign markers to a linkage group. Repetitive use of the RIPPLE command identified the best order of markers within the linkage group.

Single marker analyses (SM) and composite interval mapping (CIM) QTL analyses were conducted in individual environments and across environments to detect the main effect of chromosomal regions associated with agronomic traits by the adjusted LSMEANS for the RICLs-3A entries and QTL Cartographer 1.30 (Basten et al., 2000). Initially, SM was conducted for each trait to identify markers associated with variation for that trait. Traits with significant marker associations $(P<0.05)$ as determined by SM were further evaluated by CIM with 2-cM intervals scanned for the presence of QTL. Three-hundred permutation tests $(P<0.05)$ were conducted for CIM to establish a significance threshold to control Type-I error. For CIM analyses, no more than five background markers were used to control background effects; a 1-cM window was used. Background markers were selected by means of forward-backward stepwise regression with thresholds of $P<$ 0.1 for entering and $P<0.1$ for remaining in the model.

\section{Analysis of QTL $\times$ Environment Interactions}

ANOVA was conducted following the procedures used by Zhu et al. (1999) and Sari-Gorla et al. (1997) to partition trait variance into sums of squares due to (i) environments, (ii) incomplete block effects nested within environments, (iii) marker genotype main effects (QTL), and (iv) marker $\times$ environment interactions (MEI). Genotype and GEI were included in the model to identify if significant residual genotype and GEI variation remained after main effect QTL and QEI were placed in the model. This procedure allowed for GEI (Table 1) to be partitioned into QEI, assuming that marker loci are closely linked to QTLs.

For each trait, marker main effects and interactions were selected for the model by evaluating the variation explained by a single marker at a time. Each statistically significant marker main effect $(P<0.05)$ and MEI were included in a model ordered from the largest to smallest sums of squares. Analyses were conducted in SAS by PROC GLM coupled with the RANDOM statement (SAS, 1999) to identify the best model of QTL and QEI to explain the variance for each trait. Sequential sums of squares (Type I) were used for marker and MEI effects. After each run, statistically insignificant main effect QTL or QEI were discarded from the model and a new model was constructed, until a final model was selected that contained all significant QTL and QEI for a given trait.

\section{Stability Analysis}

Stability parameters (Eberhart and Russell, 1966) were estimated, with the seven environments, by regressing genotype means on an environmental index. The environmental index was estimated as the mean of all genotypes at a specific environment minus the grand mean. The regression coefficient

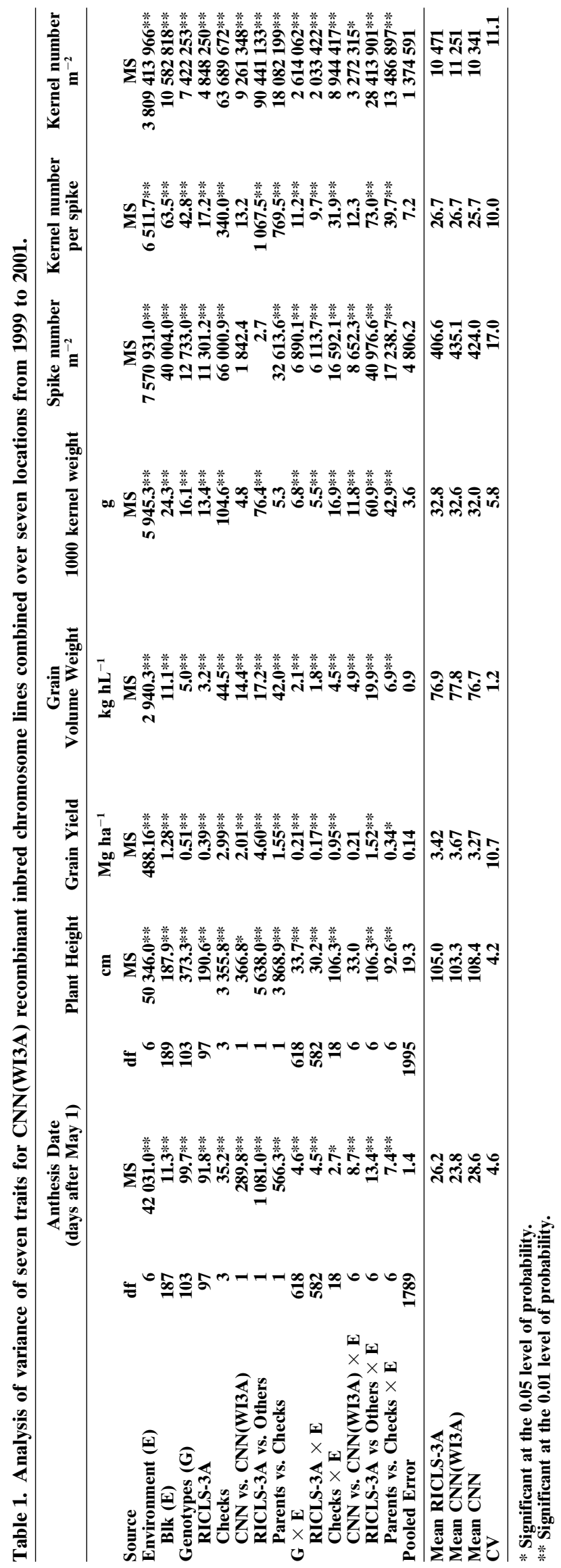


$\left(b_{i}\right)$ and deviations from regression $\left(\mathrm{S}_{\mathrm{d}}^{2}\right)$ were the parameters used to compare environmental responses of genotypes. GEI sums of squares was partitioned into sums of squares due to (i) regression of genotypes on the environmental index and (ii) pooled deviations from regression. Each partition was further broken down into sums of squares due to (i) among RICLs-3A, (ii) among check cultivars, and (iii) between CNN and CNN (WI3A) (Table 5). The GEI linear interaction mean square provided a test of genetic differences among genotypes for their response to linearly arrayed environmental productivity. The pooled deviation mean square provided a test of genetic differences among genotypes for their deviation from regression.

For an individual trait, the environmental stability of each marker detected as a main effect QTL or associated with QEI was evaluated by regressing marker genotype means on the environmental index described previously. Environmental response of each marker genotype (QTL genotype) was evaluated by means of the regression coefficient $\left(b_{i}\right)$. Regression coefficients for the two possible genotypes of a marker were compared by an $F$-test, which used the sums of squares of the pooled deviations from regression as an error term. Significantly different $b_{\mathrm{i}}$ between the two RICLs-3A genotypes possible at a given marker locus indicated that the effect of marker genotypes differed in their linear response to the environmental index.

\section{RESULTS AND DISCUSSION Field Data Analysis}

Significant differences were observed among the RICLs-3A for each of the eight traits. The two parents [CNN vs. CNN (WI3A)] differed for AD, PHT, GYLD, GVWT, and KPSM (Table 1), but not for TKWT, SPSM, and KPS. These results are in agreement with previous reports involving 50 RICLs-3A (Shah et al., 1999a), and the original chromosome 3A substitution lines (Berke et al., 1992a; Yen et al., 1997), with the exception that parents were different for TKWT in Shah et al. (1999a) and for GVWT in Berke et al. (1992a). Neither of these authors measured KPSM. RICLs$3 \mathrm{~A} \times \mathrm{E}$ interactions were significant for all of the traits, whereas the $\mathrm{CNN}$ vs. $\mathrm{CNN}$ (WI3A) $\times \mathrm{E}$ interactions were significant for AD, GVWT, TKWT, SPSM, and KPSM, but not for PHT, GYLD, and KPS. In contrast, Shah et al. (1999a) detected significant RICLs-3A $\times$ E for GYLD, TKWT, and SPSM only, and observed no significant $\mathrm{CNN}$ vs. CNN (WI3A) $\times \mathrm{E}$ for any other traits. Differences between our results and those reported by Shah et al. (1999a) are likely due to our increased statistical power using 98 RICLs-3A versus 50 RICLs-3A, incomplete block field designs, and differences between environments evaluated in both studies.

Pooled phenotypic correlations among all traits for 95 RICLs-3A were calculated to identify associations among traits (Table 2). As expected, GYLD was positively correlated with SPSM, KPSM, and GVWT but negatively correlated with AD. Hence, earlier AD and higher values for the yield components SPSM and KPSM were most associated with higher GYLD. In contrast, TKWT and KPS were not correlated with GYLD. SPSM and KPSM were negatively correlated with TKWT, which was not unexpected given the wellknown tendency for yield component traits to display compensatory effects. Highly significant phenotypic correlations between GYLD, SPSM, and KPSM are usually indicative of linked, but separate controlling genes, or pleiotropy of one common controlling gene.

\section{Molecular Markers and Linkage Analysis}

Twenty molecular markers were used to construct a linkage map of chromosome 3A. Three of the 98 RICLs$3 \mathrm{~A}$ were determined to be heterozygous for chromosome $3 \mathrm{~A}$ on the basis of the restriction pattern of several markers (presumably because of a univalent chromosome shift in their development). Inclusion of the heterozygous lines did not affect the ANOVA results. These three lines were not included in map construction or subsequent QTL analyses. Heterogeneity of marker segregation tests indicated that marker data (except for Eps) could be pooled over the two subpopulations. A Chi-square test $(P<0.01)$ indicated 1:1 segregation for 18 of the 20 markers, with the other two markers skewed somewhat toward the WI allele. These two markers were still included in the map, although their $P$-values were slightly below 0.01 because of a homogenous segregation within each subpopulation. Anthesis date (Eps) was not included as a marker in this study, as it did not show a homogeneous segregation in the RICLs-3A subpopulations. Shah et al. (1999a,b) mapped Eps as a single locus on the short arm of chromosome $3 \mathrm{~A}$ on the basis of evidence of a bimodal (1:1 segregational) distribution of the 50 RICLs-3A, although there was a slight skewing toward earliness (WI allele). However, in the second subpopulation, the 45 RICLs-3A were highly skewed toward late anthesis (CNN allele). Differences in segregation between subpopulations were most

Table 2. Phenotypic correlations of 95 CNN (WI3A) recombinant inbred chromosome lines for eight traits pooled across seven Nebraska environments.

\begin{tabular}{|c|c|c|c|c|c|c|c|}
\hline Trait $\dagger$ & PHT & GYLD & TKWT & SPSM & KPS & KPSM & GVWT \\
\hline AD & $\mathbf{0 . 5 4} * *$ & $-\mathbf{0 . 2 0} * *$ & $-0.27 * *$ & $\mathbf{0 . 1 4} * *$ & $-\mathbf{0 . 2 8} * *$ & 0.01 & 0.06 \\
\hline PHT & - & 0.02 & $-0.17 * *$ & $0.18 * *$ & $-\mathbf{0 . 1 7} * *$ & $0.12 * *$ & -0.02 \\
\hline GYLD & & - & 0.02 & $\mathbf{0 . 5 8}^{*} * *$ & 0.06 & $0.83 * *$ & $0.16 * *$ \\
\hline TKWT & & & - & $-\mathbf{0 . 4 4} * *$ & $\mathbf{0 . 0 8}^{*}$ & $-\mathbf{0 . 5 0} * *$ & $\mathbf{0 . 2 8} * *$ \\
\hline SPSM & & & & - & $-\mathbf{0 . 5 9} * *$ & $\mathbf{0 . 7 5} * *$ & 0.04 \\
\hline KPS & & & & & - & 0.00 & -0.04 \\
\hline KPSM & & & & & & - & $\mathbf{0 . 0 3}$ \\
\hline
\end{tabular}

* Significant at the 0.05 level of probability.

** Significant at the 0.01 level of probability.

$\dagger$ AD, anthesis date; PHT, plant height; GYLD, grain yield; TKWT, 1000 kernel weight; SPSM, spike number per square meter; KPS, kernel number per spike; KPSM, kernel number per square meter; GVWT, grain volume weight. 
likely a result of unintentional selection bias during the development of each RICLs-3A subpopulation. Heterogeneity within the CNN genotype used to create the RICLs-3A in each subpopulation was doubtful because a common seed source was used to develop both subpopulations. Differences in AD segregation between subpopulations could also be due to segregation of more than one locus for AD, which has been suggested by Eskridge et al. (2000) and Miura et al. (1999).

\section{QTL Identification and QTL $\times \mathbf{E}$ Interactions}

QTLs were detected for all traits except AD. QTL results from each environment and the combined analysis are summarized in Table 3. QTL scans for GYLD and KPSM within the individual and over the seven environments are shown in Fig. 1. A summary of QTLs detected across environments for all traits is shown in Fig. 2. For GYLD, we detected QTLs in four environments, for SPSM, KPSM, PHT, and TKWT in three environments, and for KPS and GVWT in two environments. Overall, three regions of chromosome $3 \mathrm{~A}$ were detected as harboring QTLs for these traits. The regions were from Xcdo549-Xtam055 (Xtam61) (Region 1), Xcdo638-Xbcd366 (Xcmwg680) (Region 2), and Xbcd366 (Xcmwg680)-Xbcd1555 (Region 3). Region 1 contained QTLs for GYLD, KPSM, PHT, KPS, and TKWT. Region 2 contained QTLs for GYLD, KPSM, TKWT, and SPSM, and Region 3 contained QTLs for PHT, GVWT, and KPS. A single QTL for KPS was detected in Lincoln 2001 in a 4th region between $X b c d 141-X b c d 372$ and a single QTL for GVWT in Lincoln 2000 was detected in a 5th region between Xbcd361-Xgwm155. In contrast, Shah et al. (1999b) were not able to detect QTLs for GYLD per se using data from 50 RICLs-3A, but did detect QTLs for PHT, TKWT, SPSM, and KPS. In that study, the chromosomal region with the largest effect was the Eps region, while other chromosomal regions contributed minor effects. The QTLs detected by Shah et al. (1999b) in other chromosomal regions (aside from Eps) corresponded to the QTLs we detected in one or more environments.

Comparing GYLD QTL detection on the basis of 95 versus 50 RICLs-3A in the current experiment indicated the effects of GYLD QTLs were greater with an increased number of RICLs-3A lines. Hence, the evaluation of 95, as opposed to 50, RICLs-3A enhanced the ability to detect QTLs for GYLD. In addition, reevaluating the initial 50 RICLs-3A population by means of the updated genetic map of chromosome 3A and CIM analyses verified the absence of GYLD QTLs expressed in the environments evaluated by Shah et al. (1999a,b). Thus, differences between the set of environments used by Shah et al. (1999a,b) and those used in the current study were responsible for GYLD QTL detection differences between the two studies. Mean values for GYLD in individual environments ranged from 1.93 to $4.67 \mathrm{Mg}$ $\mathrm{ha}^{-1}$ in the current study compared to 2.44 to $2.97 \mathrm{Mg}$ $\mathrm{ha}^{-1}$ in the previous study.

\section{Grain Yield}

For GYLD QTLs, the WI allele always increased GYLD. The QTL with largest effect was located in Region 2 (QGyld.unl.3A.2) and was identified consistently in all four environments where GYLD QTLs were detected (Fig. 1, Table 3). On the basis of the combined analysis, $Q$ Gyld.unl.3A.2 explained $28.1 \%$ of the phenotypic variance and provided an additive effect of a 66 $\mathrm{kg} \mathrm{ha}^{-1}$ increase in GYLD on the substitution of a WI

Table 3. Summary of QTLs identified by composite interval mapping for seven agronomic traits using 95 lines grown in seven individual environments and combined across environments.

\begin{tabular}{|c|c|c|c|c|}
\hline Trait & QTL & Environment & $R^{2}(\%)$ & Additive effect $\phi$ \\
\hline \multirow[t]{6}{*}{ Grain yield } & QGyld.unl.3A.1 & Combined & 6.7 & $+32 \mathbf{k g ~ h a}^{-1}$ \\
\hline & QGyld.unl.3A.2 & Lincoln 2000 & 12.8 & +82 \\
\hline & & Lincon 2001 & 17.6 & +104 \\
\hline & & Mead 2001 & 26.1 & +204 \\
\hline & & Sidney 2001 & 8.3 & +82 \\
\hline & & Combined & 28.1 & +66 \\
\hline \multirow[t]{5}{*}{ Kernel per square meter } & QKpsm.unl.3A.1 & Combined & 14.6 & $+\mathbf{1 7 0}$ kernels \\
\hline & QKpsm.unl.3A.2 & Lincoln 2000 & 15.0 & $+\mathbf{3 8 9}$ \\
\hline & & Lincon 2001 & 8.4 & +212 \\
\hline & & Mead 2001 & 20.6 & +591 \\
\hline & & Combined & 19.1 & +195 \\
\hline \multirow[t]{4}{*}{ 1000-Kernel weight } & QTkwt.unl.3A.1 & Lincoln 2001 & 14.2 & $-0.38 \mathrm{~g}$ \\
\hline & & Mead 2001 & 8.6 & $-0.34{ }^{\circ}$ \\
\hline & & Combined & 12.7 & -0.27 \\
\hline & QTkwt.unl.3A.2 & Lincoln 2000 & 12.6 & -0.63 \\
\hline \multirow[t]{3}{*}{ Plant height } & QPht.unl.3A.1 & Lincoln 1999 & 10.1 & $-1.2 \mathrm{~cm}$ \\
\hline & QPht.unl.3A.3 & Mead 2000 & 30.4 & -1.7 \\
\hline & & Sidney 2001 & 17.1 & -1.4 \\
\hline \multirow[t]{3}{*}{ Grain volume weight } & QGvwt.unl.3A.3 & Lincoln 1999 & 25.8 & $+0.29 \mathbf{k g ~ h L}^{-1}$ \\
\hline & & Combined & 43.1 & +0.23 \\
\hline & QGvwt.unl.3A.5 & Lincoln 2000 & 10.6 & $+\mathbf{0 . 1 8}$ \\
\hline \multirow[t]{4}{*}{ Spikes per square meter } & QSpsm.unl.3A.2 & Lincoln 2001 & 12.6 & +17.7 spikes \\
\hline & & Mead 2001 & 14.7 & +19.5 \\
\hline & QSpsm.unl.3A.3 & Sidney 2001 & 10.5 & +7.2 \\
\hline & & Combined & 22.8 & $+\mathbf{1 0 . 3}$ \\
\hline \multirow[t]{4}{*}{ Kernels per spike } & QKps.unl.3A.1 & Sidney 2001 & 12.8 & +0.6 kernels \\
\hline & & Combined & 15.5 & +0.3 \\
\hline & QKps.unl.3A.4 & Lincoln 2001 & 9.8 & -1.3 \\
\hline & & Combined & 9.5 & -0.3 \\
\hline
\end{tabular}

$\dagger$ Additive effect represents the substitution of a WI allele for a CNN allele. 


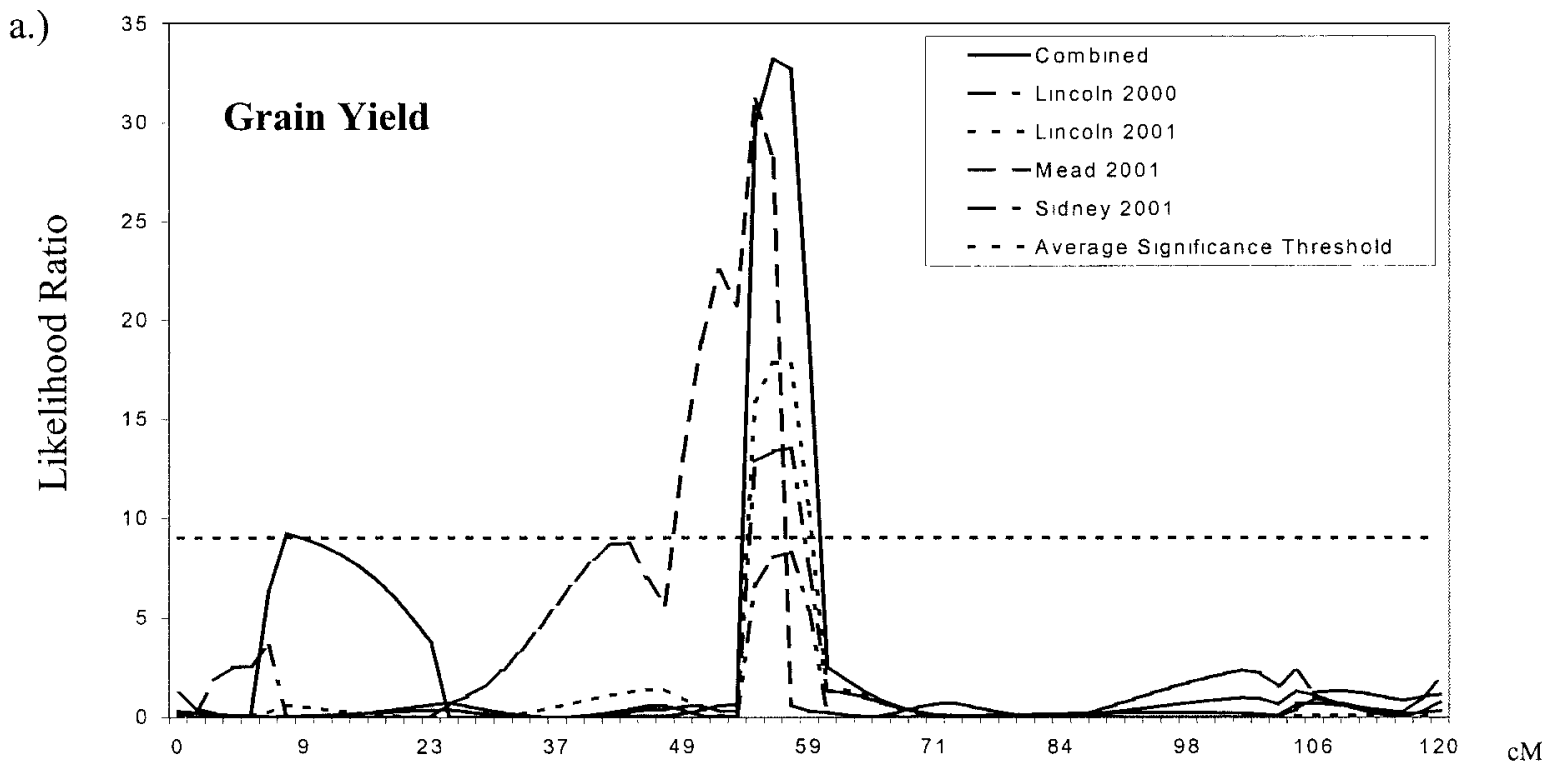

b.)

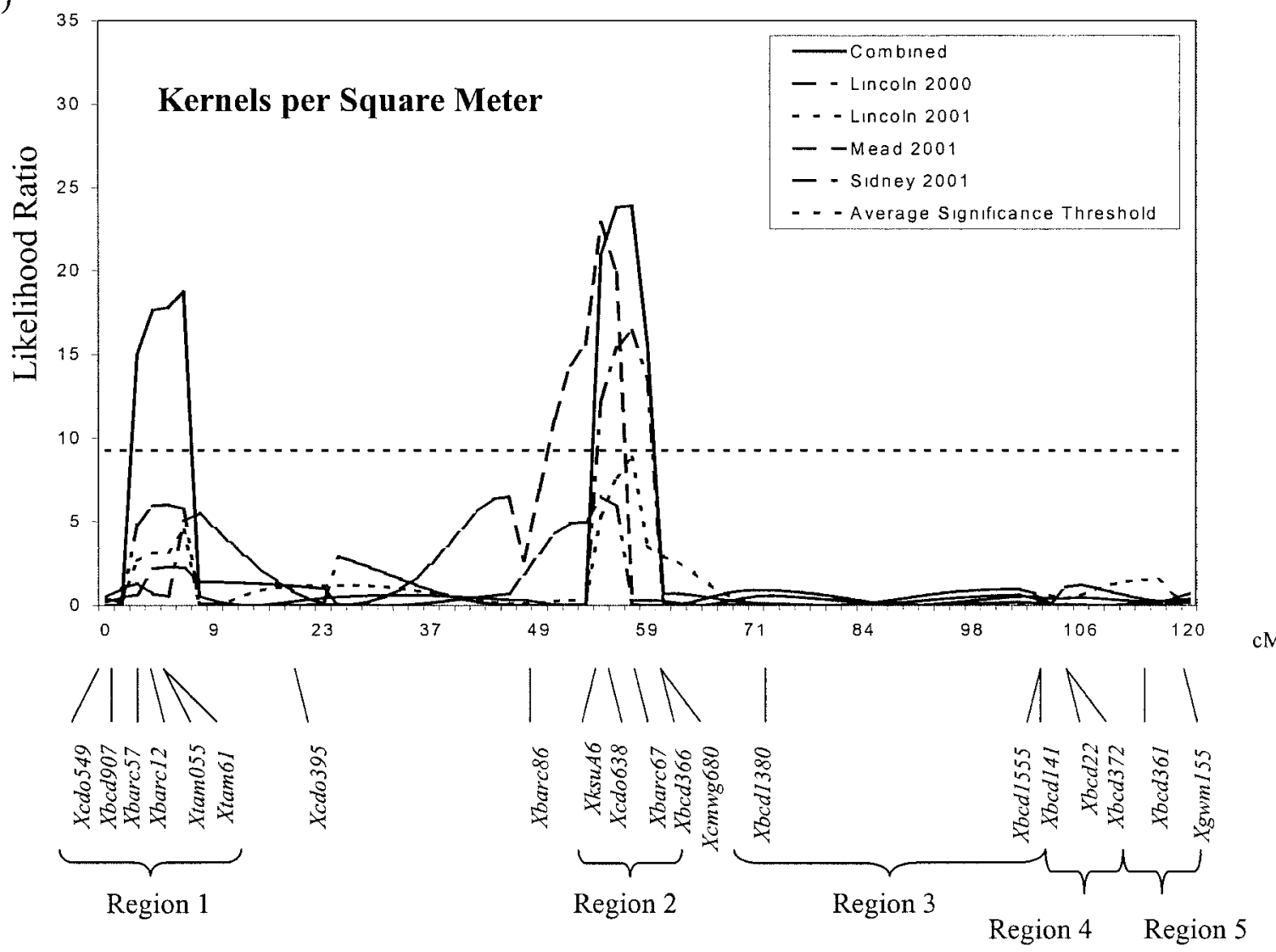

Chromosome $3 \mathrm{~A}$

Fig. 1. Composite interval mapping QTL scans along chromosome 3A showing the likely location of QTLs for (a.) grain yield and (b.) kernels per square meter using least square means from individual environments and combined across environments.

allele for a CNN allele. The minor QTL in Region 1 (QGyld.unl.3A.1) was detected in the combined analysis only and explained $6.6 \%$ of the phenotypic variance. Analysis of variance (Table 4) showed that Xbarc67 $\times \mathrm{E}$ was statistically significant, indicating QGyld.unl.3A.2 displayed sensitivity to the environment. Inability to detect the effect of QGyld.unl.3A.2 in the remaining three environments was likely due to QEI. Overall, allelic differentiation at QGyld.unl.3A.2 was greatest in higher yielding environments such as Mead 2001 and 


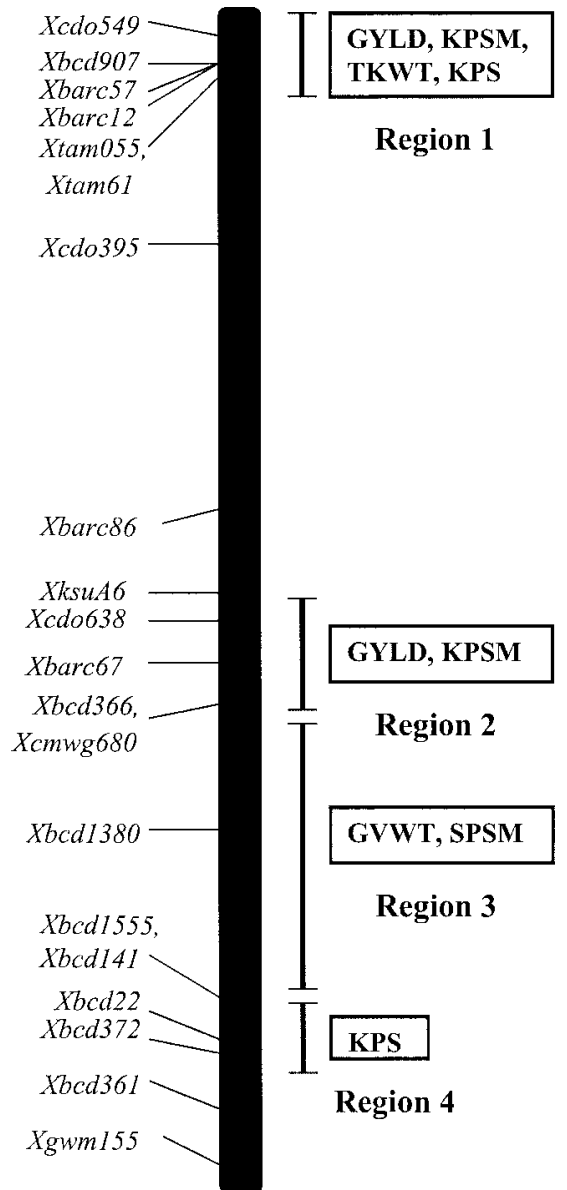

Fig. 2. Summary of the location of QTLs for grain yield (GYLD), 1000-kernel weight (TKWT), spikes per square meter (SPSM), kernels per spike (KPS), kernels per square meter (KPSM), and grain volume weight (GVWT) detected on chromosome $3 \mathrm{~A}$ across environments using composite interval mapping.

Lincoln 2001, while absent or reduced in the lowest yielding environments of Lincoln 1999 and Sidney 2001, respectively.

\section{Kernels per Square Meter}

QTLs for KPSM were detected in three of seven environments, and were localized in Regions 1 and 2 (Fig. 1, Table 3). All QTLs for KPSM were coincident with QTLs for GYLD and the WI allele always increased KPSM. The QTL with largest effect was located in Region 2 (QKpsm.unl.3A.2) explaining 19.1\% of the phenotypic variance. KPSM was increased by 195 kernels with the substitution of a WI allele for a CNN allele. The QTL in Region 1 (QKpsm.unl.3A.1) explained $14.6 \%$ of the phenotypic variance and provided an increase of 170 kernels with the substitution of a WI allele for a CNN allele. Identification of (near-)identical genomic positions with significant effects on KPSM and GYLD is consistent with a hypothesis of a single QTL with pleiotropic effects, or with the hypothesis of one (or two) QTLs for either (or both) trait(s). No line was detected with low KPSM and high GYLD or vice versa in graphs of GYLD vs. KPSM for the 95 lines, suggesting pleiotropy rather than linkage. Analysis of variance

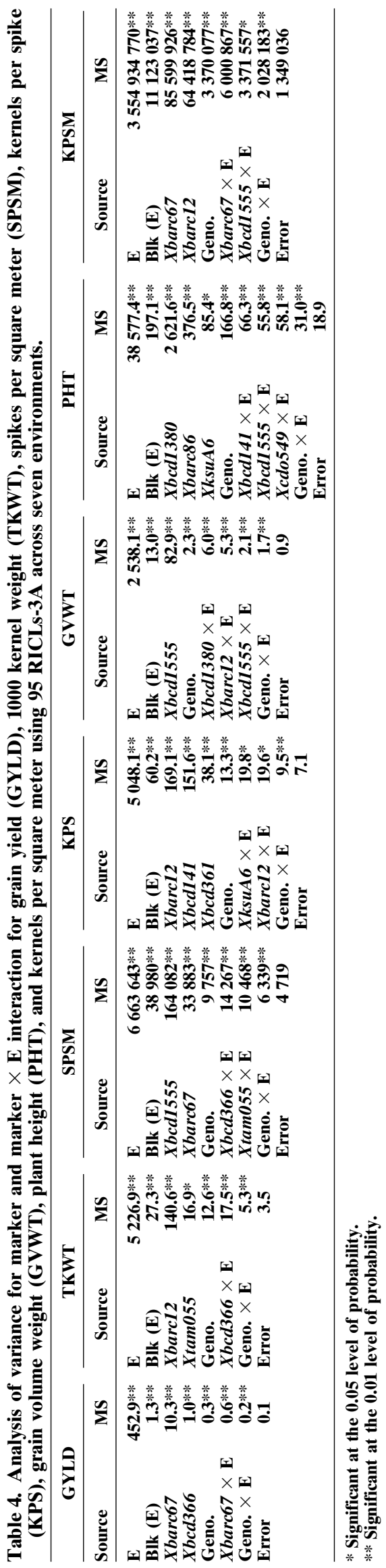


(Table 4) indicated the effect of Xbarc67 $\times \mathrm{E}$ and $X b c d 1555 \times \mathrm{E}$ were statistically significant, indicating that QKpsm.unl.3A.2 displayed sensitivity to different environmental conditions. A statistically significant QTL was not detected at $X b c d 1555$, but the significant $X b c d 1555 \times$ E interaction indicated the effect of Region 3 on KPSM was very minor overall, yet sensitive to different environments.

\section{0-Kernel Weight}

Two QTLs for TKWT were detected in three of seven environments and localized in Regions 1 and 2 (Table 3 ) with the WI allele always providing a decrease in TKWT (compared to increases in GYLD and KPSM). The QTL in Region 1 (QTkwt.unl.3A.1) was detected in two of the three environments in which QTLs were detected and in the combined analysis, and explained $12.7 \%$ of the phenotypic variance. QTkwt.unl.3A.1 provided an additive effect of a $0.27 \mathrm{~g}$ decrease in TKWT on the substitution of a WI allele for a CNN allele. QTkwt.unl.3A.2 was detected in one individual environment (Lincoln 2000) and analysis of variance (Table 4) indicated the Xbcd366 (Xcmwg680) $\times$ E interaction was significant. This interaction would explain the failure to detect QTkwt.unl.3A.2 in environments other than Lincoln 2000 if the interaction was of a skewed crossover type.

\section{Plant Height}

Statistically significant QTLs for PHT were not detected in the combined analysis. However, two QTLs for PHT were detected in three of seven individual environments, with the WI allele providing a lower value for PHT at each QTL (Table 3). QPht.unl.3A.1 was identified only in Lincoln 1999, and QPht.unl.3A.3 only in Mead 2000 and Sidney 2001. The inability to detect a main effect of QPht.unl.3A.1 and QPht.unl.3A.3 in the combined analysis and in other individual environments may have resulted from QEI detected in the analysis of variance (Table 4), with that QEI being the crossover type of interaction. Statistically significant Xcdo549 $\times \mathrm{E}$, $X b c d 1555 \times \mathrm{E}$, and $X b c d 141 \times \mathrm{E}$ interactions were detected and revealed that QPht.unl.3A.1 and QPht.unl.3A.3 displayed different effects across environments.

\section{Grain Volume Weight}

Two QTLs were detected for GVWT in two of seven environments, localized in Regions 3 (QGvwt.unl.3A.3) and 5 ( $Q G v w t . u n l .3 A .5)$, with the WI allele always providing the higher value (Table 3). QGvwt.unl.3A.3 was the only QTL detected in the combined analysis and explained $43.1 \%$ of the phenotypic variance, while providing an additive effect of increasing GVWT by 0.23 $\mathrm{kg} \mathrm{hL}^{-1}$ with the WI allele. A QTL peak was revealed in two additional environments at $Q G v w t . u n l .3 A .3$, but those peaks did not exceed the significance threshold as determined by the permutation test. The analysis of variance (Table 4) identified three statistically significant marker $\times \mathrm{E}$ interactions, including $\mathrm{Xbcd1380} \times \mathrm{E}$,
Xbarc12 $\times$ E, and Xbcd1555 $\times$ E. Xbarc12 $\times$ E indicated Region 1 was sensitive to environmental interactions and the effects of a QTL in Region 1 were below the level of detection for CIM, representing the effects of a very minor QTL. The Xbcd1380 $\times \mathrm{E}$ and $X b c d 1555 \times \mathrm{E}$ interactions indicated that the effect of Region 3 was different across environments, which may have prevented detection of $Q G v w t . u n l .3 A .3$ in more individual environments.

\section{Spikes per Square Meter and Kernels per Spike}

QTLs for SPSM were detected in three of seven environments and localized in Regions 2 (QSpsm.unl.3A.2) and 3 (QSpsm.unl.3A.3) (Table 3), with the WI allele always providing the higher value for SPSM. QSpsm.unl.3A.3 was the only QTL detected in the combined analysis, explaining $22.8 \%$ of the phenotypic variance and providing a small increase of 10.3 SPSM with the WI allele. The effect of QSpsm.unl.3A.2 was detected in two individual environments (Lincoln 2001, Mead 2001), but not the combined analysis. Analysis of variance revealed significant interactions for $X b c d 366$ $($ Xcmwg680 $) \times \mathrm{E}$ and Xtam055 $($ Xtam61) $\times \mathrm{E}$, indicating Regions 2 and 3 were sensitive to the environment for SPSM. For KPS, two QTLs (QKps.unl.3A.1 and QKps.unl.3A.4) were detected in the combined analysis, with the WI allele providing the higher value at QKps.unl.3A.1 and the lower value at QKps.unl.3A.4. Analysis of variance (Table 4) indicated the Xbarc12 $\times \mathrm{E}$ interaction was statistically significant, revealing that QKps.unl.3A.1 displayed sensitivity to environmental interactions. A significant environmental interaction was also detected for $X k s u A 6 \times \mathrm{E}$ and revealed that the effect of Region 3 was sensitive to the environment.

\section{Environmental Interactions and Genotype Stability}

Partitioning GEI (linear) into RICLs-3A (linear), parents (linear), and checks (linear) revealed significant differences in slope $\left(b_{i}\right)$ among the RICLs-3A (linear) for PHT, GVWT, and TKWT and between the parents (linear) for SPSM and KPSM (Table 5). Hence, genotypes within the RICLs-3A population responded dissimilarly to a low to high gradient of environmental indicies for PHT, GVWT, and TKWT. The parents [CNN and CNN (WI3A)] also responded dissimilarly over the same gradient and indicies for SPSM and KPSM.

Regressing QTL genotype means on an environmental index indicated that some QTL genotypes exhibited different responses across environmental conditions (Fig. 3). For GYLD, four markers [Xbarc86, XksuA6, Xbarc67, and Xbcd366 (Xcmwg680)] showed differences in slope between marker genotypes and were localized in Region 2, where a major QTL for GYLD was detected. The difference in slope between the two marker genotypes, represented by Xbarc67 in Fig. 3a, was due to a change in magnitude. The increasing phenotypic differential between the two Xbarc67 genotypes was greater in more productive environments, with the 
Table 5. Partitioning of genotype $\times$ environment interactions into linear and nonlinear components. Mean squares and significance levels of $F$-tests from the regression analysis of all traits for 98 RICLs-3A, check cultivars, parents, RICLs-3A vs. others, and parents vs. check cultivars combined over seven environments from 1999 to 2001.

\begin{tabular}{|c|c|c|c|c|c|c|c|c|c|c|}
\hline Source & df & $\begin{array}{c}\text { Anthesis } \\
\text { date } \\
\text { MS }\end{array}$ & df & $\begin{array}{c}\text { Plant } \\
\text { height } \\
\text { MS }\end{array}$ & $\begin{array}{c}\text { Grain } \\
\text { yield } \\
\text { MS }\end{array}$ & $\begin{array}{c}\text { Grain } \\
\text { volume } \\
\text { weight } \\
\text { MS }\end{array}$ & $\begin{array}{c}\text { 1000- } \\
\text { kernel } \\
\text { weight } \\
\text { MS }\end{array}$ & $\begin{array}{c}\text { Spike } \\
\text { number } \\
\text { m }^{-2} \\
\text { MS }\end{array}$ & $\begin{array}{c}\text { Kernel } \\
\text { number } \\
\text { per spike } \\
\text { MS }\end{array}$ & $\begin{array}{c}\text { Kernel } \\
\text { number } \\
\text { m }^{-2} \\
\text { MS }\end{array}$ \\
\hline Genotypes & 103 & $30.7 * *$ & 103 & $103.4 * *$ & $0.14 * *$ & $1.3 * *$ & $4.4 * *$ & $35^{28}$ *** & $12.5^{* *}$ & $2092692 * *$ \\
\hline Environment (linear) & 1 & $63435.4 * *$ & 1 & $75534.5 * *$ & 732.18** & $4410.8 * *$ & $8918.1 * *$ & $11356425 * *$ & $9768.3 * *$ & $5714120613 * *$ \\
\hline $\mathbf{G} \times \mathbf{E}$ (linear) & 103 & 0.5 & 103 & $15.4 * *$ & 0.07 & $1.4 * *$ & $4.3 * *$ & 2209 & 3.6 & $915568 * *$ \\
\hline RICLs-3A (linear) & 97 & 0.5 & 97 & 13.0* & 0.05 & $1.3 * *$ & $2.9 * *$ & 2043 & 2.5 & 654352 \\
\hline Checks (linear) & 3 & 0.2 & 3 & $67.7 * *$ & $\mathbf{0 . 3 4} * *$ & 0.2 & $8.6^{* * *}$ & 2610 & $27.3 *$ & $4275250 * *$ \\
\hline Parents (linear) & 1 & 0.2 & 1 & 0.1 & 0.14 & 0.6 & 4.5 & $9800 *$ & 0.2 & $4060729 *$ \\
\hline RICLs-3A vs. Others (linear) & 1 & 0.8 & 1 & 81.1** & $0.91 * *$ & $15.5^{* *}$ & $76.3 * *$ & $9457 *$ & 23.2** & $11943301 * *$ \\
\hline Parents vs. Checks (linear) & 1 & 0.6 & 1 & $40.7^{*}$ & 0.05 & $4.6 * *$ & $47.5 * *$ & 2342 & $21.9 * *$ & 2001602 \\
\hline Pooled deviations & 520 & $1.6 *$ & 520 & 10.0 & 0.06 & 0.6 & 1.7 & 1865 & 3.3 & 684901 \\
\hline RICLs-3A dev. & 490 & $1.6^{*}$ & 490 & 9.3 & 0.05 & 0.5 & 1.5 & 1698 & 3.0 & 576093 \\
\hline Checks dev. & 20 & 2.0 & 15 & 24.5 & $0.24 * *$ & $2.9 * *$ & 4.8 & 6072 & 10.1 & 3483517 ** \\
\hline Parents dev. & 10 & 1.3 & 5 & 12.7 & 0.04 & 0.2 & 1.6 & 1611 & 4.8 & 419248 \\
\hline Pooled Error & 1789 & 1.4 & 1995 & 19.3 & 0.1 & 0.9 & 3.6 & 4860 & 7.2 & 1374591 \\
\hline
\end{tabular}

* Significant at the 0.05 level of probability.

** Significant at the 0.01 level of probability.

WI allele always providing a higher value than the CNN allele. Similarly, Berke et al. (1992b) found that differences between grain yield for CNN (WI3A) and CNN were greater in higher yielding environments.

Four markers localized in Region 1 displayed statistically different marker genotype slopes for PHT (Xcdo549, Xbarc12, Xtam055 (Xtam61), and Xcdo395), and another marker $(X b c d 1380)$ displayed statistically different marker genotype slopes for TKWT. For PHT and TKWT, differences in slope between marker alleles were due to crossover interactions, with the WI allele providing the higher value in environments conducive to shorter PHT and lower TKWT. Crossover interactions for the effects of marker genotypes on PHT and
TKWT QTL are represented by $X c d o 549$ and $X b c d 1380$, respectively (Fig. 3b,c).

For KPS, three markers [Xbarc12, Xtam055 (Xtam61), and $X b c d 141]$ displayed differences in slope between marker genotypes and were localized in Regions 1 and 3 . Differences in slope between marker genotypes for Xbarc12, Xtam055 (Xtam61), and Xbcd141 were due to changes in magnitude, with greater differences between genotypes in higher KPS environments, as illustrated by Xtam055 (Xtam61) and Xbcd141 (Fig. 3d). Xbarc12 and Xtam055 (Xtam61) always displayed higher values for KPS with the WI allele, but Xbcd141 always displayed higher values for the $\mathrm{CNN}$ allele. These results indicate that alleles for these two QTLs were in repul-

a.)

Xbarc67 (QGyld.unI.3A.2)

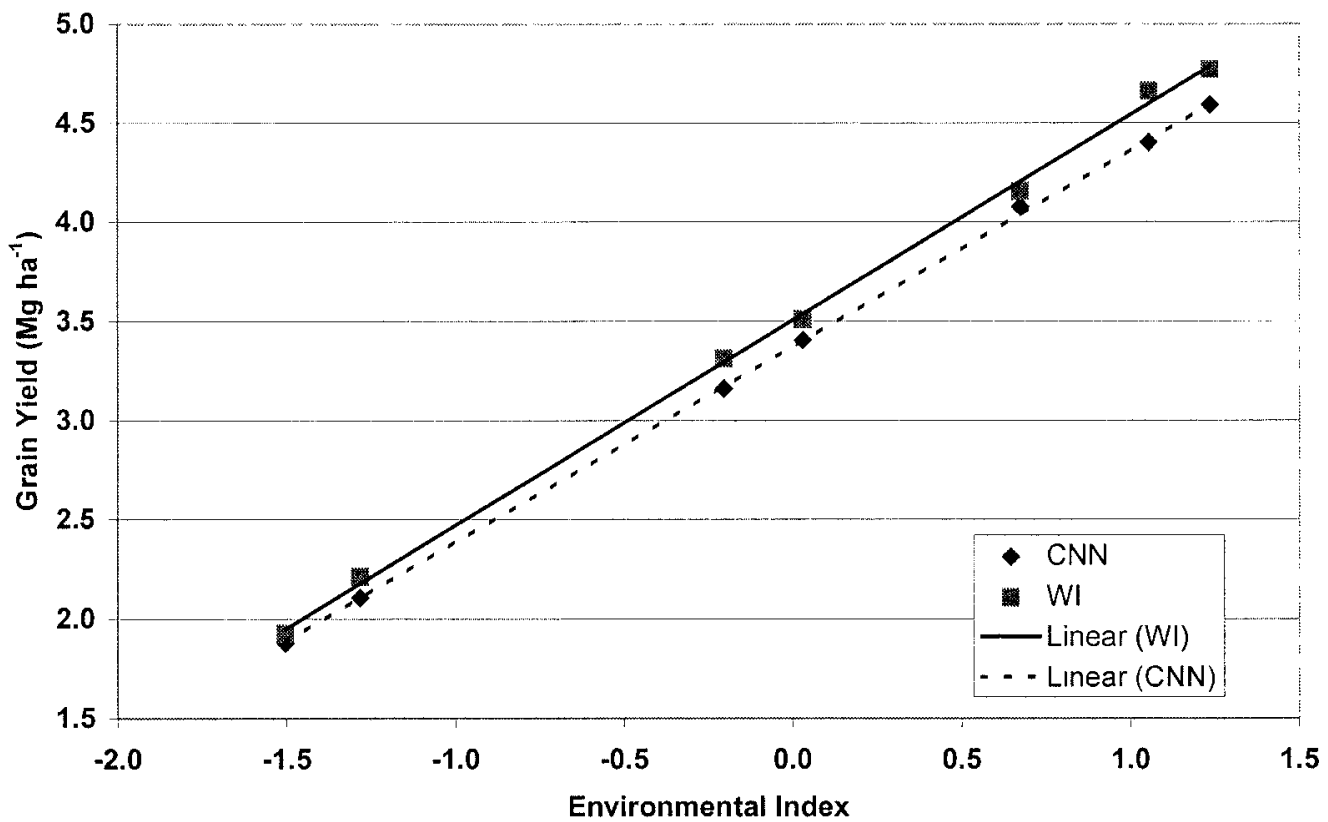

Fig. 3. Statistically significant regressions of marker genotype mean on an environmental index estimated from the mean of marker genotypes grown in each of seven Nebraska environments minus the grand mean for: a.) grain yield (GYLD), b.) plant height (PHT), c.) 1000-kernel weight (TKWT), and d.) kernels per spike (KPS). 
b.)

\section{Xcdo549 (QPht.unl.3A.1)}

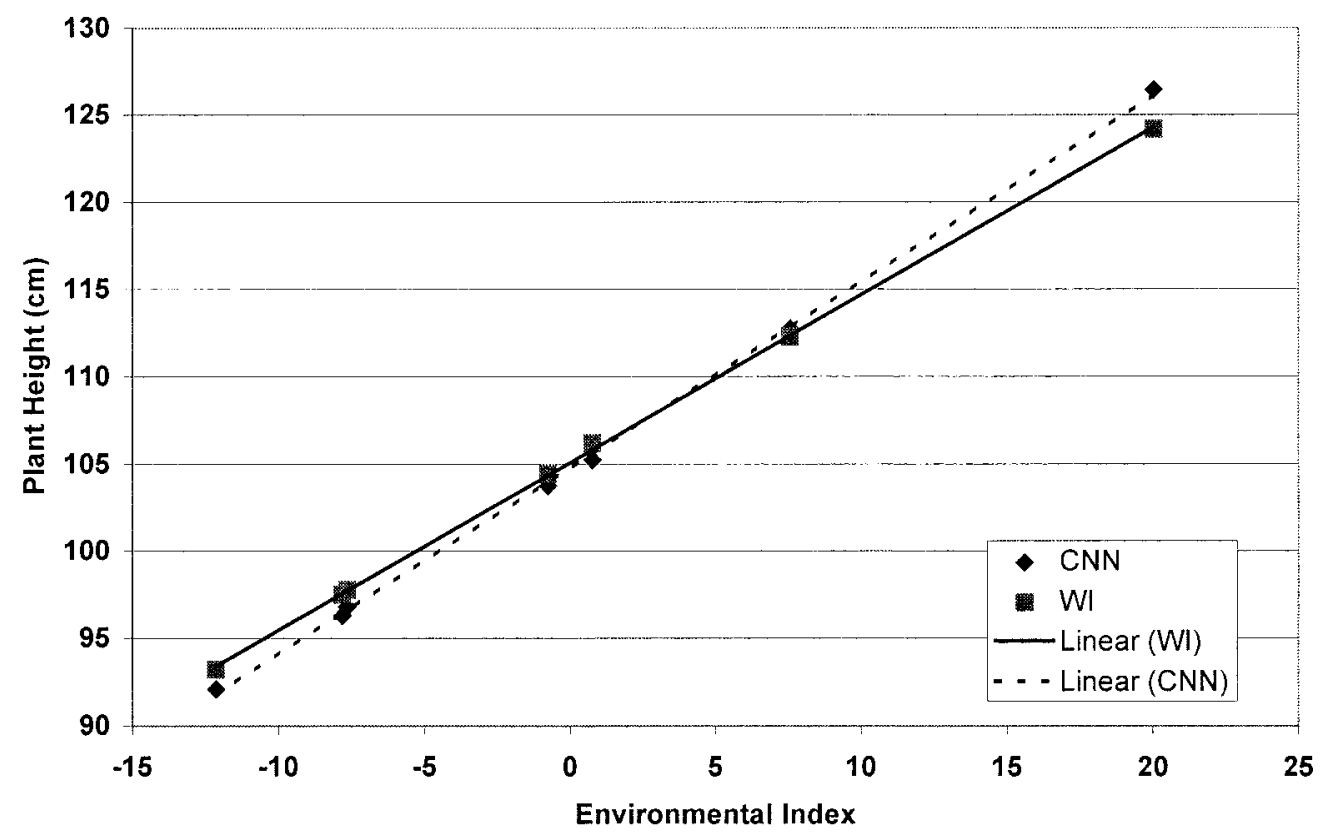

c.)

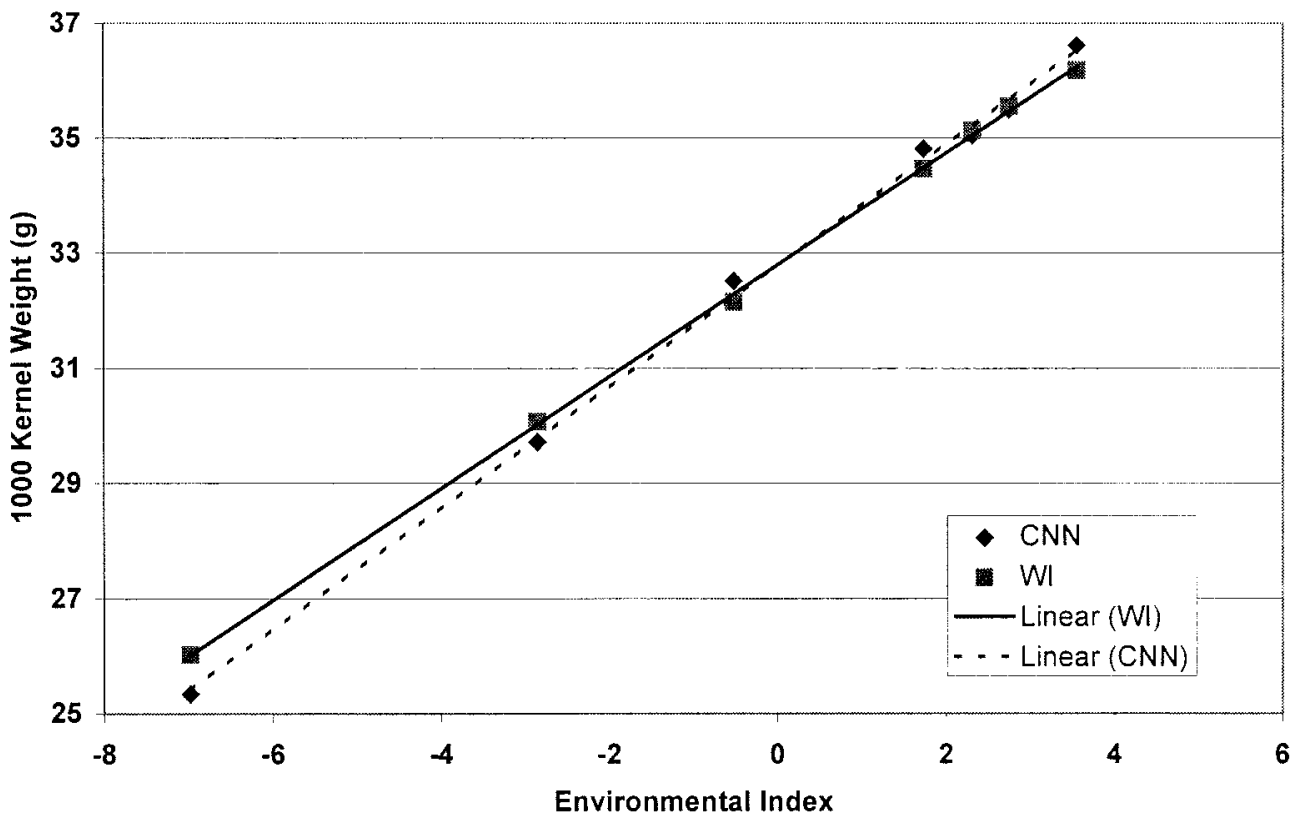

Fig. 3. Continued.

on chromosome $3 \mathrm{~A}$ of wheat by means of a population sion phase. No statistically significant differences in marker genotype slopes were detected for KPSM, SPSM, and GVWT.

\section{CONCLUSIONS}

This experiment clearly shows that QTLs and QEI associated with agronomic performance can be detected of 95 RICLs-3A. Although these conclusions apply to the present population of RICLs-3A and the Nebraska environments they were evaluated in, our goal was to provide a general idea of the nature of QTLs affecting agronomic performance on chromosome $3 \mathrm{~A}$ and their interactions with the environment. QEI analyses indicated some QTLs were sensitive to different environ- 
d.)

Xtam055 (QKps.unI.3A.1)

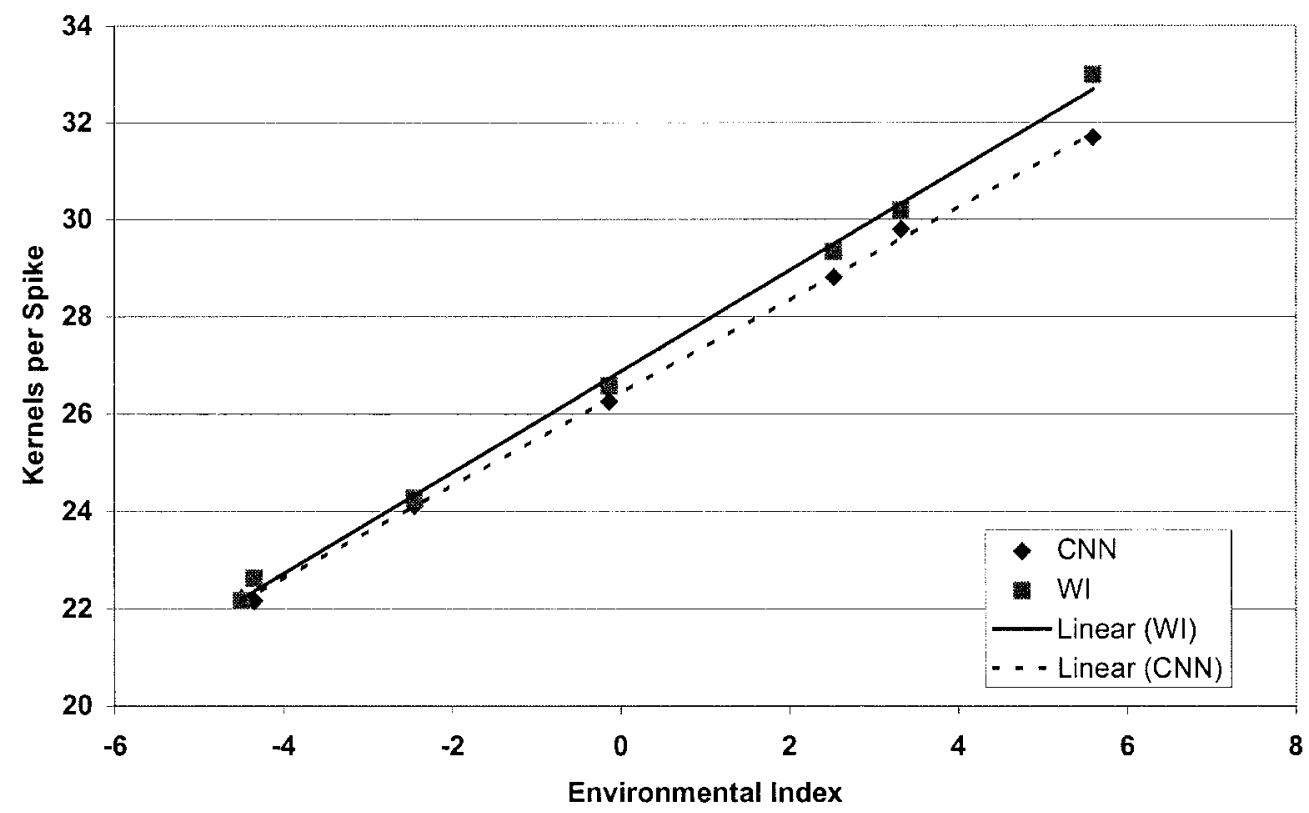

e.)

Xbcd141 (QKps.unl.3A.3)

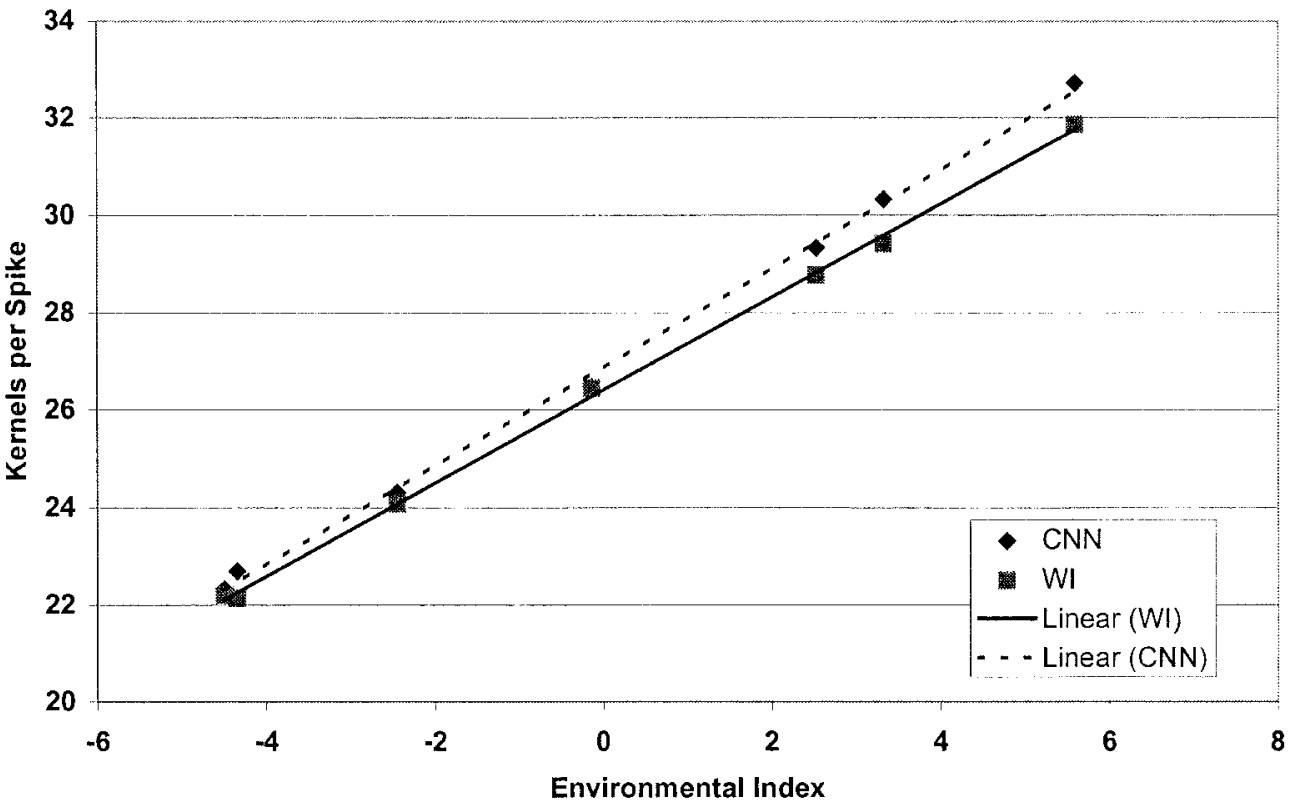

Fig. 3. Continued.

mental conditions, displaying interactions caused by either changes in magnitude of the QTL effect and crossover interactions.

Major QTLs for GYLD and KPSM were identified in Region 2 [Xcdo638-Xbcd366 (Xcmwg680)] and most likely represented a single, major QTL for KPSM displaying pleiotropic effects on GYLD. Other studies in wheat using RICLs for chromosomes $4 \mathrm{~A}$ and $5 \mathrm{~A}$ indicate that grain yield QTLs are always detected concurrently with QTLs for yield component traits or other developmental traits (Araki et al., 1999; Kato et al., 2000). This implies that effects of QTLs detected for grain yield are simply due to the effects of QTLs for one or more yield component (and other) traits, which would be expected because of the complex nature of grain yield and common associations with other agronomic traits.

Overall, the analysis of variance approach used to detect QEI, coupled with regressing QTL genotype means on an environmental index, resulted in a better 
understanding of QEI relative to comparing QTL detection across environments. One advantage of conducting the regression of QTL allelic means on an environmental index approach was that QEI could be assessed in terms of a magnitude difference (e.g.- QGyld.unl.3A.2) or crossover type (e.g.- QPht.unl.3A.1, QTkwt.unl.3A.2). Our approach at dissecting QEI revealed that expression of the favorable allele at the major GYLD QTL QGyld.unl.3A.2 (WI allele) was greatest (in terms of magnitude) in higher yielding environments such as Lincoln 2001 and Mead 2001 and lowest or absent in lower yielding environments such as Lincoln 1999 and Sidney 2001. Identifying and understanding environmental differences contributing to $Q$ Gyld.unl.3A.2 expression differences highlights the importance of understanding QTL expression across environments before selecting for QTLs associated with higher grain yield in a breeding program.

In contrast to QGyld.unl.3A.2, QEI detected for PHT and TKWT were due to crossover interactions, as the WI allele provided the higher value in lower PHT and TKWT environments and the lower value in higher PHT and TKWT environments, but apparently not having an appreciable effect on grain yield interaction. The crossover type of interactions for these PHT and TKWT QTLs limited their detection across environments and led to a nonsignificant QTL main effect in the combined analysis. Large GEI and QEI for PHT was not surprising, as Budak et al. (1995) reported difficulty in selecting consistently tall, non-semidwarf genotypes in eastern $\mathrm{Ne}$ braska for western Nebraska. WI, CNN, CNN (WI3A), and the RICLs-3A are conventional height, non-semidwarf lines. The environmentally sensitive QTLs for PHT and TKWT detected in this study clearly illustrate the importance of determining if QEI are due to changes in magnitude or crossover interactions before using MAS to select for QTLs, because identifying and selecting the proper allele at QTLs with crossover interactions requires careful selection in target environments. Inappropriate allele identification or selection could result in the indirect selection of QTL alleles with detrimental effects in some target environments.

\section{ACKNOWLEDGMENTS}

We thank Dr. Jim Specht and Dr. Don Lee for helpful discussions and review of the manuscript.

\section{REFERENCES}

Araki, E., H. Miura, and S. Sawada. 1999. Identification of genetic loci affecting amylose content and agronomic traits on chromosome 4A of wheat. Theor. Appl. Genet. 98:977-984.

Arumuganathan, K., and D.E. Earle. 1991. Nuclear DNA content of some important plant species. Plant Mol. Biol. Rep. 9:208-218.

Basten, C.J., B.S. Weir, and Z.B. Zeng. 2000. QTL Cartographer. Version 1.15. A reference manual and tutorial for QTL mapping. Department of Statistics, North Carolina State University, Raleigh, NC.

Beavis, W.D., and P. Keim. 1996. Identification of quantitative trait loci that are affected by environment. p. 123-149. In M.S. Kang and H. G. Gauch Jr. (ed.) Genotype by environment interaction. CRC Press, Boca Raton, FL.

Berke, T.G., P.S. Baenziger, and R. Morris. 1992a. Chromosomal location of wheat quantitative trait loci affecting agronomic perfor- mance of seven traits, using reciprocal chromosome substitutions. Crop Sci. 32:621-627.

Berke, T.G., P.S. Baenziger, and R. Morris. 1992b. Chromosomal location of wheat quantitative trait loci affecting stability of six traits, using reciprocal chromosome substitutions. Crop Sci. 32: 628-633.

Budak, N., P.S. Baenziger, K.M. Eskridge, D. Baltensperger, and B. Moreno-Sevilla. 1995. Plant height response of semidwarf and nonsemidwarf wheats to the enivronment. Crop Sci. 35:447-451.

Cantrell, R.G., and L.R. Joppa. 1991. Genetic analysis of quantitative traits in wild emmer (Triticum turgidum var. dicoccoides). Crop Sci. 31:645-649.

Dudley, J.W. 1993. Molecular markers in plant improvement: manipulation of genes affecting quantitative traits. Crop Sci. 33:660-668.

Eberhart, S.A., and W.A. Russell. 1966. Stability parameters for comparing varieties. Crop Sci. 6:36-40.

Edwards, M.D., C.W. Stuber, and J.F. Wendel. 1987. Molecular marker-facilitated investigations of quantitative trait loci in maize. I. Numbers, distribution, and types of gene action. Genetics 116: 113-125.

Eskridge, K.M., M.M. Shah, P.S. Baenziger, and D.A. Travnicek. 2000. Correcting for classification errors when estimating the number of genes using recombinant inbred chromosome lines. Crop Sci. 40: 398-403.

Gill, K.S., E.L. Lubbers, B.S. Gill, W.J. Raupp, and T.S. Cox. 1991 A genetic linkage map of Triticum tauschii (DD) and its relationship to the D genome of bread wheat (AABBDD). Genome 34:362-374.

Hayes, P.M., B.H. Liu, S.J. Knapp, F. Chen, B. Jones, T. Blake, J. Franckowiak, D. Rasmusson, M. Sorrells, S.E. Ullrich, D. Wesenberg, and A. Kleinhofs. 1993. Quantitative trait locus effects and environmental interaction in a sample of North American barley germ plasm. Theor. Appl. Genet. 87:392-401.

Joppa, L.R., D. Changheng, G.E. Hart, and G.A. Hareland. 1997. Mapping gene(s) for grain protein in tetraploid wheat (Triticum turgidum L.) using a population of recombinant inbred chromosome lines. Crop Sci. 37:1586-1589.

Kaeppler, S.M. 1997. Quantitative trait locus mapping using sets of near-isogenic lines: relative power comparisons and technical considerations. Theor. Appl. Genet. 95:384-392.

Kang, M.S. 1993. Simultaneous selection for yield and stability in crop performance trials: consequences for growers. Agron. J. 85:754757.

Kato, K., H. Miura, and S. Sawada. 1999. QTL mapping of genes controlling ear emergence time and plant height on chromosome 5A of wheat. Theor. Appl. Genet. 98:472-477.

Kato, K., H. Miura, and S. Sawada. 2000. Mapping QTLs controlling grain yield and its components on chromosome $5 \mathrm{~A}$ of wheat. Theor. Appl. Genet. 101:1114-1121.

Lander, E., and D. Botstein. 1989. Mapping Mendelian factors underlying quantitative traits using RFLP linkage maps. Genetics 121: 185-199.

Lin, C.S., M.R. Binns, and L.P. Lefkovitch. 1986. Stability analysis: Where do we stand? Crop Sci. 26:894-900.

Lincoln, S., M. Daly, and E. Lander. 1992. Constructing genetic maps with MAPMAKER/EXP 3.0. Whitehead Institute Technical Report. Whitehead Institute, Cambridge, MA.

Liu, B.-H. 1997. Statistical genomics: Linkage, mapping, and QTL analysis CRC Press, New York.

Lu, C., L. Shen, Z. Tan, Y. Xu, P. He, and L. Zhu. 1997. Comparative mapping of QTLs for agronomic traits across environments by using a doubled-haploid populaiton. Theor. Appl. Genet. 94:145150.

Miura, H., N. Nakagawa, and A.J. Worland. 1999. Control of ear emergence time by chromosome 3A of wheat. Plant Breed. 118:85-87.

Paterson, A., S. Damon, J. Hewitt, D. Zamir, H. Rabinowitch, S. Lincoln, E. Lander, and S. Tanksley. 1991. Mendelian factors underlying quantitative traits in tomato: comparison across species, generations, and environments. Genetics 127:181-197.

Peterson, C.J. 1992. Similarities among test sites based on cultivar performance in the hard red winter wheat region. Crop Sci. 32: 907-912.

Röder, M.S., V. Korzun, K. Wendehake, J. Plaschke, M.H. Tixier, P. 
Leroy, and M.W. Ganal. 1998. A microsatellite map of wheat. Genetics 149:2007-2023.

Saghai-Maroof, M.A., K.M. Soliman, R.A. Jorgensen, and R.W. Allard. 1984. Ribosomal DNA spacer-length polymorphisms in barley: Mendelian inheritance, chromosomal location, and population dynamics. Proc. Natl. Acad. Sci. (USA) 81:8014-8018.

Sari-Gorla, M., T. Calinski, Z. Kaczmarek, and P. Krajewski. 1997. Detection of QTL $\times$ environment interaction in maize by a least squares interval mapping method. Heredity 78:146-157.

SAS Institute. 1999. The SAS system for windows. Release 8.2. SAS Inst., Cary, NC.

Shah, M., P. Baenziger, Y. Yen, K. Gill, B. Moreno-Sevilla, and K. Haliloglu. 1999a. Genetic analyses of agronomic traits controlled by wheat chromosome 3A. Crop Sci. 39:1016-1021.

Shah, M.M., K.S. Gill, P.S. Baenziger, Y. Yen, S.M. Kaeppler, and H.M. Ariyarathne. 1999b. Molecular mapping of loci for agronomic traits on chromosome 3A of bread wheat. Crop Sci. 39:1728-1732.
Stuber, C.W., M.D. Edwards, and J.F. Wendel. 1987. Molecular marker-facilitated investigations of quantitative trait loci in maize. II. Factors influencing yield and its component traits. Crop Sci. 27:639-648.

Tanksley, S.D., H. Medina-Filho, and C.M. Rick. 1982. Use of naturally-occurring enzyme variation to detect and map genes controlling quantitative traits in an interspecific backcross of tomato. Heredity 49:11-25.

Yen, Y., and P.S. Baenziger. 1992. A better way to construct recombinant inbred chromosome lines and their controls. Genome 35: 827-830.

Yen, Y., P.S. Baenziger, R. Burns, J. Reeder, B. Moreno-Sevilla, and N. Budak. 1997. Agronomic performance of hybrids between cultivars and chromosome substitution lines. Crop Sci. 37:396-399.

Zhu, H., G. Briceno, R. Dovel, P.M. Hayes, B.H. Liu, C.T. Liu, and S.E. Ulrich. 1999. Molecular breeding for grain yield in barley: An evaluation of QTL effects in a spring barley cross. Theor. Appl. Genet. 98:772-779. 